\title{
PERINATAL OUTCOME OF PREMATURE RUPTURE MEMBRANE IN PREGNANCY
}

\author{
BEGUM $\mathrm{H}^{1}$, ROY $\mathrm{M}^{2}$, SHAPLA $\mathrm{NR}^{3}$
}

\begin{abstract}
:
Objective: To find out the effect of PROM on neonatal outcome so that we can pay more attention for the correct diagnosis and management of PROM in pregnancy which can reduce the perinatal mortality and morbidity caused by PROM.

Methods: One hundred PROM cases were selected maintaining appropriate inclusion \& exclusion criteria from the department of obstetrics \& Gynaecology of BSMMU \& DMCH and one hundred controlled cases were taken from the same during the period of January 2010 to December 2010. Data were analyzed with SPSS statistical program to determine the effect of PROM on neonatal health.

Results: In this study, 44\% babies of PROM patients had various type of morbidity compare to $24 \%$ of patients with intact membrane. In PROM patients, perinatal mortality was $7 \%$ in this study compare to $5 \%$ with intact membrane. Causes of perinatal death in PROM was severe asphyxia (4\%), RDS (5\%) \& neonatal sepsis (6\%) mainly.

Conclusion: All fetal complications were significantly higher in PROM patients who received treatment after prolonged rupture of membrane. Appropriate antibiotic coverage in appropriate time will reduce fetal morbidity.
\end{abstract}

Key words: PROM, Pregnancy, foetal/neonatal outcome.

J Dhaka Med Coll. 2017; 26(2) : 135-139

\section{Introduction:}

Premature rupture of membranes (PROM) is defined as spontaneous rupture of the membranes any time beyond 28 weeks of pregnancy but before the onset of labour. It occurs approximately $10 \%$ of all pregnancies ${ }^{2}$. Rupture of the membranes before onset of labour at a gestational age $<37$ completed weeks or before term which is called pre-term premature rupture of membranes ${ }^{1}$. If 24 hours elapse between the rupture of the membranes and the onset of labour, the problem is one of prolonged premature rupture of the membranes ${ }^{2}$.

Premature rupture of membranes in preterm gestations (PROM) occurs in approximately $2 \%$ of all pregnancies ${ }^{3}$ and is associated with 30$40 \%$ of preterm birth with complications, which may be associated with high rate of neonatal morbidity and mortality. Premature rupture of membranes complicates $4-7 \%$ of all births and is directly associated with short gestational length and increased perinatal and neonatal morbidity ${ }^{4}$. Premature rupture of membranes (PROM) in the midtrimester of 16 to 26 weeks gestation complicate almost $1 \%$ of pregnancies ${ }^{5}$. It can occur either with or without bleeding and infection ${ }^{6}$. Currently overall infant survival after delivery at 24-26 weeks of gestation is reported to be between $50 \%$ and $75 \%{ }^{7}$. Survival rate in pregnancies complicated by PROM are comparable but decreased in the presence of infection or deformation. A small number of patient with mid trimester have extended latency period, the mean latency period ranged from 10.6-21.5 days ${ }^{8}$. The study was aimed to find out the effect of PROM on neonatal health so that we can pay more attention for the correct diagnosis and management of PROM which can reduces the mortality and morbidity caused by PROM.

1. Major Housneara Begum, BSS-101706, Classified specialist Obs \& Gynae, Address: Adhoc CMH Ramu, Ramu Cantonment.

2. Major Marlina Roy, BSS-101714, Classified specialist Obs \& Gynae, Address: CMH Dhaka, Dhaka Cantonment.

3. Lt. Col. Nahid Reaz Shapla, Classified specialist OBS \& Gynae, Address: Adhoc CMH Ramu, Ramu Cantonment.

Address of correspondence: BSS-101706, Dr. Housneara Begum, MBBS, FCPS, E-mail: munamorshed@yahoo.com 


\section{Materials \& Methods:}

One hundred PROM cases were selected of which 60 from department of Obstetrics \& Gynecology of Dhaka Medical College Hospital $(\mathrm{DMCH}) \& 40$ cases were selected from the department of Obstetrics \& Gynaecology of Bangabandhu Sheikh Mujib Medical University (BSMMU) and one hundred controlled cases were taken of which 60 from department of Obstetrics \& Gynecology of Dhaka Medical College Hospital \& 40 cases were selected from the department of Both hospitals are tertiary level teaching hospital where management protocol for PROM patients were similar. Fetal monitoring by CTG was available in both hospitals.

Patients with gestational age more than 28 weeks duration, spontaneous rupture of membrane before the initiation of labour and both primigravida and multigravida were included. Women who were admitted with rupture membrane with established labour, rupture membrane with anti-partum hemorrhage, severe pre-eclampsia, eclampsia were excluded from this study.

High vaginal swab was taken from all patients and send for culture $\&$ sensitivity. On admission blood sample was sent for CBC(total leucocyte count),CRP,URINE R/M/E for every patient. The gestational age of patient was determined by the menstrual history, previous antenatal records, USG and clinical examination. Data analysis was done with SPSS statistical program.

\section{Results:}

The present study intended to identify rupture membrane and its effect on fetus included a total of 100 patients with gestational age more than 28 weeks duration, spontaneous rupture of membrane before the initiation of labour and both primigravida and multigravida. Age of the patient ranged between 15-39 years. Majority belongs to the age group of 20-29 years. Most of the patients with premature rupture of membrane came from middle and poor socioeconomic condition. Majority of the patient of PROM who came for hospital delivery had irregular antenatal check-up (50\%). Thirty two percent cases had regular check-up and 18\% cases had no antenatal check-up. Forty percent of PROM patients were primi and $60 \%$ of patients were multi gravid. Fifty eight percent patients with intact membrane were primi and $42 \%$ patients were multigravid. Fifty five percent of PROM cases were at term pregnancy. At the same time $45 \%$ cases were preterm premature rupture of membrane (pPROM). Among pPROM $5 \%$ cases were $<34$ weeks pregnancy. On the other hand patient in labour with intact membrane $90 \%$ were at term pregnancy and $10 \%$ were preterm. Only $2 \%$ found $<34$ weeks pregnancy.

Among 100 cases of patients with PROM, 39 patients had associated diseases during present pregnancy; most common disease was UTI $(56.41 \%)$ and next was lower genital tract infection (15.38\%). Among patients with intact membrane (17 patients) had associated disease and common disease of which was UTI (35.29\%) and hypertension was next (29.41\%). Seventy percent of PROM cases had sexual contact within one week of rupture of membrane and $23 \%$ cases with intact membrane had sexual contact more then one week. Among the 100 PROM patients, 39 patients had previous history of gynecological and obstetrical problems of which previous preterm delivery and previous PROM were high.

Cervical effacement was $0-30 \%$ in majority $(68 \%)$ of PROM patients on admission. Cervical Dilatation was $<2 \mathrm{~cm}$ in majority ( $75 \%$ ) of PROM patients on admission. Majority of the term PROM patient $(80 \%)$ developed labour pain within 24 hours (95\%) within 72 hours of rupture membrane. Ten patients had no onset of labour pain.Among the preterm PROM 35$50 \%$ goes in labour within 24 hours. Onset of labour was spontaneous in $46 \%$ of cases and induced in $31 \%$ of cases. Sixty two percent of patients delivered within 24 hours of ruptured membrane, $25 \%$ delivered within 48 hours and $13 \%$ after 48 hours of ruptured membrane. Preterm premature rupture of membrane is more common in multigravid among preterm delivery, caesarian section (LUCS) is more common in primi-gravid women. 
Table- I

Perinatal Outcome

\begin{tabular}{lcc}
\hline Outcome & $\begin{array}{c}\text { No. of Babies of } \\
\text { PROM patient } \\
\text { (n-100) }\end{array}$ & $\begin{array}{c}\text { No. of Babies of } \\
\text { intact membrane } \\
\text { Patient (n-100) }\end{array}$ \\
\hline No complication & 56 & 76 \\
Hyaline membrane disease & 10 & 03 \\
Pulmonary hypoplasia & 06 & 01 \\
Neonatal jaundice & 10 & 05 \\
Birth asphyxia & 05 & 06 \\
Foetal deformities(facial \&skeletal deformities due & 04 & 03 \\
to severe ,prolonged oligohydramnios) & & 01 \\
Congenital malformation & 01 & 01 \\
Still Birth & 01 & 04 \\
Perinatal death(mainly due to prematurity \& & 07 & \\
its complications) & & \\
\hline
\end{tabular}

In this study, $56 \%$ babies of PROM patients had no abnormality and 44\% had various types of morbidity compare to $24 \%$ of patients with intact membrane. In PROM patients, perinatal mortality was $7 \%$ in this study compare to $5 \%$ with intact membrane. Causes of perinatal death in PROM was severe asphyxia, RDS \& neonatal sepsis mainly. However, in patients with intact membrane, main causes of death were prolonged obstructed labour and fetal distress.

\section{Discussion}

Premature rupture of membranes is one of the common complications of pregnancy that has a major impact on foetal and maternal outcome. It is one of the commonest clinical events where a traditional pregnancy can turn into high risk situation for the mother as well as the foetus.

In this study, conducted in BSMMU \& $\mathrm{DMCH}$ shows the hospital incidence of PROM as $12.25 \%$. Fifty five percent of PROM cases occur in term pregnancy and $45 \%$ occur in preterm pregnancy. These results are of no difference in comparison to other studies 6-19 percent $^{2}$, 5-10 percent ${ }^{38}$ and 2.7-17 percent $^{36}$. Dr. Tasnim $\mathrm{S}^{30}$ in her study showed hospital incidence of $\mathrm{PROM}$ as $8.12 \%$ at $\mathrm{DMCH}$ in 1995 which is almost similar to my study result. In this study mean age of PROM was found $25 \pm 4$ years, which is similar to other study by Michael Moretti et $\mathrm{al}^{31}$, Begum A Chowdhury ${ }^{32}$ and Dr. Tasnim $\mathrm{S}^{30}$. In this study the incidence of PROM was $60 \%$ in multigravid while that of $40 \%$ in primigravid. Begum A Chowdhury ${ }^{32}$ showed incidence of PROM in multigravia is about $70 \%$ and Michael Moretti et $\mathrm{al}^{31}$ showed that of $71 \%$ which are similar to my study result.

Regarding perinatal outcome, out of 100 PROM cases $55 \%$ babies were mature \& $45 \%$ babies were premature ${ }^{13}$. Three percent babies had weight below $2 \mathrm{~kg}, 64 \%$ of babies had weight between $2-3.5 \mathrm{~kg}$ and $7 \%$ of babies had weight above $3.5 \mathrm{~kg}$. In control group 94\% babies were mature, $6 \%$ babies were premature, $3 \%$ babies had birth weight below $2 \mathrm{~kg}, 60 \%$ babies had birth weight between $2-3.5 \mathrm{~kg}$ and $37 \%$ babies had birth weight above $3.5 \mathrm{~kg}$ which is nearly similar to the study of Begum $\mathrm{D}^{34}$. In this study, $56 \%$ babies of PROM patients had no abnormality and $44 \%$ had various type of morbidity compare to $24 \%$ of patients with intact membrane which is almost similar to the study of Taylor $\mathrm{J} \&$ Garite $\mathrm{TJ}{ }^{18}$.

In PROM patients, perinatal mortality was $7 \%$ in this study compare to $5 \%$ with intact membrane. Causes of perinatal death in PROM were severe birth asphyxia, RDS \& neonatal sepsis mainly. However, in patients with intact 
membrane, main cause of death were prolonged obstructed labour and fetal distress. In present study both perinatal mortality and morbidity were lower than the previous studies of Begum A Chowdhury ${ }^{32}$, Tasnim $\mathrm{S}^{30}$, Begum $\mathrm{D}^{34}$. This may due to improved neonatal care in BSMMU and also in $\mathrm{DMCH}$.

\section{Conclusion}

PROM in pregnancy causes serious hazard to the fetus. The clinical course of PROM is usually characterized by increased fetal morbidity \& mortality. prevention of PROM requires identification of women at risk of PROM \& adequate means of treatment.most important high risk factors are previous preterm delivery due to PROM,vaginal bleeding during pregnancy,maternal smoking, taking more than three cup of coffe per day in $1^{\text {st }}$ trimester, repeated genital infections\& recurrent UTI, history of LEEP(loop electrosurgical excision procedure) or laser procedure in the cervix for the treatment of cervical intraepithelial neoplasia. The ultimate goal of management must be towards the safe perinatal outcome. When patients present with prolonged rupture of membranes, chance of infectious morbidity is higher. Earlier the patient reach to the hospital with least intervention outside, better the outcome. Appropriate antibiotic coverage in appropriate time will reduce fetal infectious morbidity. Proper health education, motivation of patient, improved health hygiene, regular antenatal care, adequate maternal and child care services, improved transport system are needed for reduction of perintal morbidity and mortality.

\section{References}

1. Arne Ohlsson, MD. Treatment of preterm rupture of membranes: A metanalysis AMJ Obstet Gynecol April 1989; 160: No 4.

2. Alan H. Decherney, Lauren Nathan. Current Obstetrics \& Gynecologic Diagnosis and Treatment, $9^{\text {th }}$ edition, 292-294.

3. D. Keith Edmond, Dewhurst- Text book of Obstetrics and Gynaecology, $7^{\text {th }}$ edition, Oxford university press 2007: p-190.

4. James A. Mc Gregor, MDCM, Janice I. French, CNM, MS, David Lawellinm PhD, Amalia Franco, Buff, MS, Craig Smith, BA, AND James K. Todd, MD; Bacterial protease induced reduction of chorioamnionitic membrane strength and elasticity. Obstet Gynecol 1987; 69; 167-174.
5. Johnson JWC, Egerman RS, Moorhead J. Cases with ruptured membranes that "reseal". Am J Obstet Gynecol 1990; 163: 1024-1032.

6. Kilpatrick SJ, Schlueter MA, Piecuch R, Leona $\mathrm{CH}$, Rogido M, Sola A. Outcome of infant born at 24-26 weeks' gestation: I. survival \& cost. Obstet Gynecol 1997;90:803-808.

7. Schucker JL, Mercer BM. Midtrimester premature rupture of the membranes. Semin Perinatol 1996; 20: 389-400.

8. Schmidt W. The amniotic fluid compartment: the fetal habitat. Adv Anat Embryol Cell Biol 1992; 127: 1100 .

9. Casey ML, MacDonald PC. Interstitial collagen synthesis and processing in human amnion: a property of the mesenchymal cells. Biol Reprod 1996; 55: 1253-1260.

10. Malak TM, Ockleford CD, Bell SC, Dalgleish R, Bright $\mathrm{N}$, Macvicar J. Confocal immunofluorescence localization of collagen types I, III, IV,V and VI and their ultrastructural organization in term human fetal membranes. Placenta 1993; 14:385-406.

11. Datta DC- Premature Rupture of Membranes: Text Book of Obstetrics $6^{\text {th }}$ edition. New central book agency Pvt. Ltd., Calcutta, India 2005: 317-318.

12. Dawood MY, Ylikorkala O, Trivedi D. Fuchs F, Oxytocin in Maternal circulation and amniotic fluid during pregnancy.

13. French JI, Mcgregor JA. The pathobiology of premature rupture of membranes. Semin Perinatol 1996; 20; 344-368.

14. Taylor J, Garite TJ. Premature rupture of the membranes before fetal viability. Obstet Gynecol 1984; 64: 615-620.

15. Harger JH, Hsing AW, Tuomala RE, Gibbs RS, Mead PB, Escheenbach DA, et al. Risk factor for preterm premature of fetal membranes: a multicenter case control study. Am J obstet Gynecol 1990;163:130137.

16. Novak-Antolic Z, Pajantar M, Verdenik I. Rupture of the membranes and post partum infection. Eur $\mathrm{J}$ Obstet Gynecol Reprod Biol 1997;71:141-146.

17. Williams PL, Narwich R, Dayson M. Bannister LH, editor. In: Gray's Anatomy. $37^{\text {th }}$ ed. Churchil livingstone 1989.

18. Casey ML, Mac Donald PC: The endothelin / enkephalinase of human fetal membranes and chorionic vessels. Abstract presented at $39^{\text {th }}$ annual meeting of society for gynaecological investigation. San Antinio, March 1992.

19. Sbarra AJ, Thomas GB, Cetrulo CL, et al: Effect of Bacterial growth on bursting pressure of foetal membrane in vitro. Obstet Gynaecol 1987; 70: 107110 . 
20. Spinello-A; Capuzzo-E; Stronati-M; Ometto-A; Orusl$\mathrm{S}$ : Fazzi-effect of preterm premature rupture of membrane on neurodevelopment outcome: follow up at two years of ago. By obstetrics and gynaecology Nov. 1995. Vol. 102. pp 882-887.

21. Skoll MA, Mercer BM, Baselski V, et al: Evaluation of rapid group B streptococcal antigen tests in labour and delivery patients. Obstet Gynecol 1991; 77: 32226.

22. Vintzileos AM, Campbell WA, Nochimson DJ, et al: The foetal biophysical profile in patients with premature rupture of the membranes- An early predictor of foetal infection. Am J obstet Gynecol 1985; 152: 510-516.

23. Vintzileos AM, Campbell WA, Nochimson DJ, et al: The use of nonstress test in patients with premature rupture of membranes. Am J Obstet Gynecol 1986; 155: 149-153.

24. Mercer B, Dahmus M, Rodriguez J, et al: perinatal outcome with premature rupture of the membranes and fetal pulmonary maturity, abstract 288, San Antonio, $38^{\text {th }}$ Meeting of the Society for Gynecologic investigation, 1991.

25. Vintzileos AM, Campbell WA, Rodies JF, Nochimson DJ, Pinette MJ, Petrikovosky BM. Comparison of 6 different ultrasonographic methods for predicting lethal fetal pulmonary hypoplasia. Am J Obstet Gynecol. 1989;161: 606-612.

26. Nelson DM, Stempel L E. Zuspan FP. Association of prolonged premature rupture of the membranes \& abruptio placentae. J Reprod Med 1986; 31: 249.

27. Fernando Arias. Practical Guide to High Risk Pregnancy and delivery, $2^{\text {nd }}$ edition, Harcourt Brace \& Company Asia PTE LTD, p100-109.
28. Kenyon S. Boulvain M \& Neilson J (2003) Antibiotics for inhibiting preterm labour with intact membranes; Cochrane Database Syst Rev 4, CD000246, Review.

29. Jackson RJ; Uao-ML-Lim-UVAB. Cell Associated collagenolytic activity group B streptococci, infectimmune; 1994 Uac 62 (12) 5647-51.

30. Dr. Tasnim S: Clinical profile \& outcome of pregnancy in premature rupture of membrane in $\mathrm{DMCH}-\mathrm{A}$ study of fifty five cases. Dissert 1995.

31. Michael Moretti MD, \& Baha M. Sibai MD: Maternal and perinata outcome of expectant management of rupture of membranes in the mid trimester. Am J Obstet Gynecol 1988: 159; 390-396.

32. Begum A. Chowdhury: A clinical evaluation of PROM 60 cases, J Inst Postgrad Med. Res 1991; 11-15.

33. Samuel Parry, MD., and Jeoome F. Strauss III, MD, PhD- Premature Rupture of Foetal Membranes, The New England Journal of Medicine 1998; 338: No.10, 663-670.

34. Begum D: Maternal and Foetal complications of premature rupture of membranes. Dissert 1997.

35. Yoon J, Harper R: Observation on the relationship between duration of rupture of membranes and the development of idiopathic respiratory distress syndrome. Pediatrics 1973; 52: 161.

36. Gold RB, Goyert GL, Schwartz DB, Evans MI, Seabolt LA. Conservative management of second trimester post amniocentesis fluid leakage. Obstet Gynecol 1989;74: 745-747.

37. Mercer BM. Management of premature rupture of membranes before 26 weeks' gestation. Obstet Gynecol Clin North Am 1992; 19: 339-351.

38. David E. Soper, MD, C. Glen Mayhall, MD \& Harry P. Dalton PhD. Risk factors for intramniotic infection: A prospective epidemiologic study. 